\title{
Flight rapidly modulates body temperature in freely behaving bats
}

\author{
Jinhong Luo ${ }^{1 *+}$ (D), Stefan Greif ${ }^{2,3+}$, Huan Ye , Sara Bumrungsri ${ }^{4}$, Ofri Eitan ${ }^{2,3}$ and Yossi Yovel ${ }^{2,3^{*}}$
}

\begin{abstract}
Background: Bats are remarkable in their dynamic control over body temperature, showing both hypothermia with torpor and hyperthermia during flight. Despite considerable research in understanding bats' thermoregulation mechanisms, knowledge on the relationship between flight and body temperature in bats remains limited, possibly due to technological restraints.

Results: We used onboard dataloggers including a temperature sensor and an inertial sensor (accelerometers) and continuously recorded the flight behavior and skin temperature $\left(T_{s k}\right)$ subcutaneously of a perch-hunting bat, Hipposideros armiger, both in the laboratory and in the field. We provide evidence that flight increases the body temperature of bats. The median of the maximum increase in the $T_{\text {sk }}$ caused by flight bouts was $3.4^{\circ} \mathrm{C}$ (between 1.9 and $5.3^{\circ} \mathrm{C}$ for different individuals) in the laboratory. The maximum $T_{s k}$ for the bats was narrowly centered around $40^{\circ} \mathrm{C}$ (between 38.5 and $40.9^{\circ} \mathrm{C}$ ). Moreover, we found that the faster the $T_{s k}$ rises, the greater the maximum increase in $T_{s k}$. Interestingly, bats can slow down the $T_{\text {sk }}$ rises with intermittent fights, during which they perch after brief flight bouts to allow the body temperature to drop rapidly. Similar data were collected from field recordings in free-ranging bats.

Conclusions: We suggest that perch-hunting behavior observed in approximately 200 species of bats that results in intermittent flights may function as a thermoregulatory strategy, in addition to optimizing energy efficiency as demonstrated by previous studies.
\end{abstract}

Keywords: Chiroptera, Energetics, Foraging strategy, Heterotherm, Thermoregulation

\section{Background}

Bats are the second largest mammalian order and are widely distributed across the world [1]. Among several remarkable features of bats, dynamic control of body temperature over an extended range has attracted researchers' attention for decades [2-8]. From a comparative perspective, several aspects of the body temperature in bats are of interest. First, bats can perform many typical activities in a much larger range of body

\footnotetext{
*Correspondence: jluo@ccnu.edu.cn; yossiyovel@gmail.com

${ }^{\dagger}$ Jinhong Luo and Stefan Greif contributed equally to this work

1 Hubei Key Laboratory of Genetic Regulation \& Integrative Biology, School of Life Sciences, Central China Normal University, Wuhan, China

${ }^{2}$ School of Zoology, Faculty of Life Sciences, Tel Aviv University, Tel Aviv, Israel

Full list of author information is available at the end of the article
}

temperatures than most mammals. For example, several species of bats can fly at a body temperature as low as $24{ }^{\circ} \mathrm{C}[9,10]$, which is more than $10^{\circ} \mathrm{C}$ below the homeothermic zone of $35-39^{\circ} \mathrm{C}$. Second, on a daily basis, many species of bats reduce their body temperature by many degrees based on the ambient environment to conserve energy, entering a special physiological status called torpor [5-7]. Some bats can also hibernate during the wintertime and their body temperature can be as low as a few degrees Celsius. Third, probably due to their unique ability of powered flight as a mammal, the body temperature of flying bats often surpasses the higher limit of their homeothermic zone $[4,9,11]$. Both hypothermia (torpor and hibernation) and hyperthermia (fever) are hypothesized to be related to the evolution of their exceptional immune system for defending ectoparasites and diseases original author(s) and the source, provide a link to the Creative Commons licence, and indicate if changes were made. The images or other third party material in this article are included in the article's Creative Commons licence, unless indicated otherwise in a credit line to the material. If material is not included in the article's Creative Commons licence and your intended use is not permitted by statutory regulation or exceeds the permitted use, you will need to obtain permission directly from the copyright holder. To view a copy of this licence, visit http://creativecommons.org/licenses/by/4.0/. The Creative Commons Public Domain Dedication waiver (http://creativeco mmons.org/publicdomain/zero/1.0/) applies to the data made available in this article, unless otherwise stated in a credit line to the data. 
[12-14], in addition to important physiological functions ranging from energy conservation to survival in hot conditions $[4,6,15]$.

Over the years, several methods have been used to measure the body temperature of bats. Traditionally, fast-responding thermocouples were used to measure the rectal and skin temperatures for both hanging and flying bats $[9,16]$. Thermocouples give instant temperatures and often require manual reading and noting. Thus, the body temperature of flying bats was all measured in a post-flight fashion after catching the bats $[9,10]$. Miniature temperature sensors now allow continual body temperature monitoring and have been employed intensively for studying resting bats, particularly bats in hibernation or daily torpor $[5,17-22]$. A few studies also applied thermal infrared imaging techniques to measure freely flying bats in the field [23-25]. These measurements allow detailed temperature comparisons between various body parts, but do not allow tracking an individual's temperature over time, since they only allow measuring animals directly in front of the device. To date, there have been very few reports of continuous measurements of body temperature in flying bats [26].

In this study, we first conducted a literature review to evaluate the previous use of the available techniques for measuring body temperature in bats. Then, we present pilot data from synchronized measurements of the body temperature and flight behavior of free-flying great roundleaf bats (Hipposideros armiger) in the laboratory and in the wild, using onboard temperature and acceleration dataloggers (Fig. 1). The primary goal was to examine the potential of using onboard temperature sensors to quantify wild bat physiology and to provide new insight into the physiology of bats as they are flying in their natural environment. Early studies with thermocouples have shown that, shortly after flight onsets, the bat's core body temperature rises $[10,16,27]$. Thus, we were keen to validate these findings in free-flying bats in the real world.

\section{Results}

\section{Research status of body temperature measurements in bats}

Based on the online database Web of Science and our literature library, we identified a total of 179 studies reporting the body (skin) temperature of bats. Body temperature has been measured for 163 bat species from 14 families (Fig. 2A). Bats from the family Vespertilionidae are most intensively studied, representing $39 \%$ of the total, which was followed by the family Phyllostomidae and family Pteropodidae. Overall, there was an increase in the number of studies on the body temperature of bats over the years (Fig. 2B). In particular, the number of published studies during the past 30 years (1990-2020) represents $79 \%$ of the total studies. Methodologically,
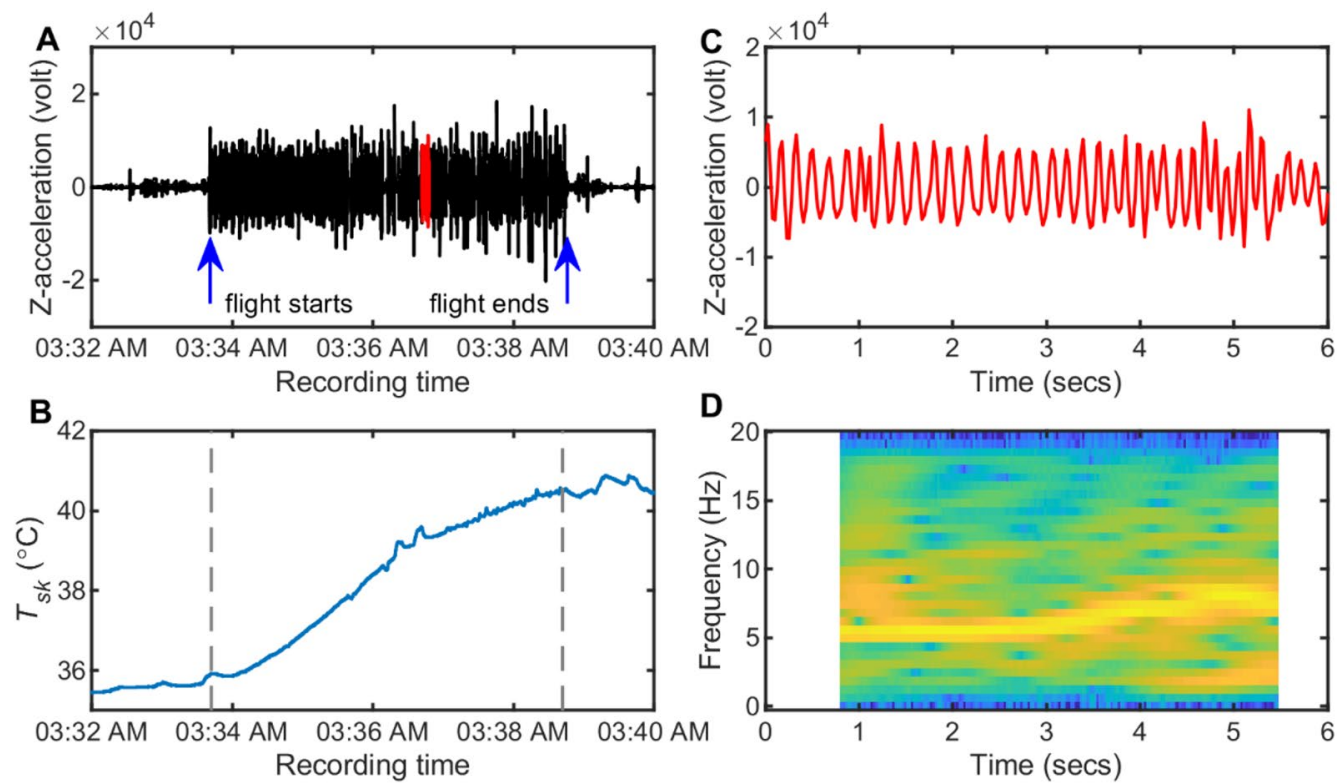

Fig. 1 An illustration of the measurements of the body temperature and the flight behavior of a bat in the laboratory. A Z-acceleration can be used to identify the flight bouts of bats. When a bat starts to fly, the $z$-acceleration is characterized by a sudden increase in amplitude. When the bat stops flying, the z-acceleration amplitude returns to the baseline level. B The synchronized measurement of the $T_{\text {sk }}$ surrounding the flight bouts as shown in A. C, D The zoom-in view and the spectrogram of the acceleration data for the section highlighted in red in $\mathbf{A}$. The energy distribution of the spectrogram for the $z$-acceleration reflects the wingbeat frequency of the flying bat (which is centered around $6.8 \mathrm{~Hz}$ ) 

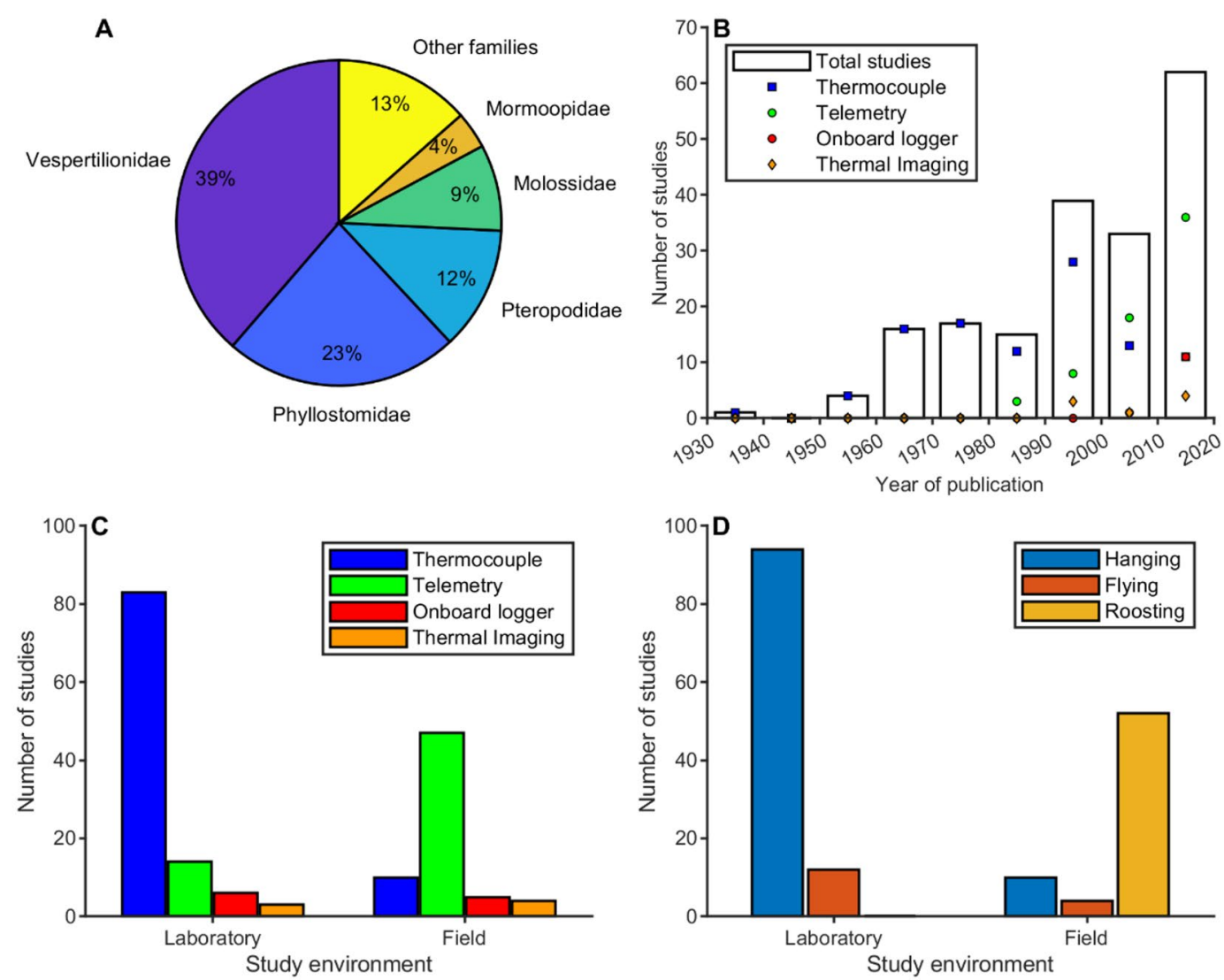

Fig. 2 Research status on the body temperature of bats. A The proportion of the bat species from different families that the body temperature was measured. 'Other families' includes the families in which the number of species is less than six. B Counts of the studies on bat body temperature every decade since the year 1930, as well as the number of studies grouped by the measurement technique for each study. C Counts of the studies based on the measurement technique for both the laboratory and field studies. D Counts of the studies based on the behavior of the bats for both the laboratory and field studies. 'Roosting' behavior describes the studies that were carried out for bats at the roost and the bats can show both hanging and flying behavior, although the specific behavior of the bats during the recording was typically unknown. Seven of the studies used two measurement techniques and these studies were counted as two separate studies. Both the 'Telemetry' and 'Onboard logger' technique rely on miniature temperature sensors attached to the bat

three measurement techniques were employed in studying bats' body temperature: thermocouples, temperature sensors (temperature telemetry and onboard loggers), and thermal infrared-light imaging. Except for eight studies that used thermal infrared-light imaging techniques, all other studies either used thermocouples or temperature sensors. Before 1980, thermocouples were used for all, except one, of the 39 studies. Afterward, miniature temperature sensors were used more and more frequently. For the past two decades, 68 of 93 studies (73\%) applied temperature sensors to measure the body temperature of bats. When studies were grouped by the study environment, it revealed that thermocouples were the dominant measurement device for studying bats' body temperature in the laboratory, while temperature telemetry was the most popular technique for recording bats' body temperature in the field (Fig. 2C). Regarding the behavioral context of the bats for the body temperature measurements, hanging bats and roosting bats were most commonly studied in the laboratory and the field, respectively (Fig. 2D). Notably, only four studies have recorded the body temperature of flying bats in the field and none of these studies collected flight data in parallel to the body temperature measurements as we did.

\section{Body temperature and flight behavior of $\mathrm{H}$. armiger in the laboratory}

We made synchronized and continuous recordings of the skin temperature $\left(T_{s k}\right)$ and wingbeat behavior of 8 individual bats, using onboard temperature sensors and inertial sensors (accelerometers) in the laboratory. The temperature sensor was implanted subcutaneously, and 
thus measures an intermediate between the skin and the (core) body temperatures and is affected by ambient temperature to a lesser degree than external sensors (Additional file 1: Fig. S1). Example recordings of both the $T_{s k}$ and the flight-induced acceleration from a bat are shown in Fig. 1A, B. Based on the change in the amplitude of the $\mathrm{z}$-axis acceleration, flight bouts were identified (see "Methods"). The trace of the $T_{s k}$ of individual bats is characterized by rapid changes during identified flight bouts (Fig. 1A, B). Across the 8 individuals of bats recorded, the medians of the minimum and maximum $T_{s k}$ were 34.6 and $39.9{ }^{\circ} \mathrm{C}$, respectively. The median $T_{s k}$ was $36.0{ }^{\circ} \mathrm{C}$. Both the median and the maximum $T_{s k}$ were more similar across individuals, compared with the minimum $T_{s k}$ (Fig. 3B). Specifically, the variation of the median and the maximum $T_{s k}$, as measured by the range, were $27 \%$ and $19 \%$ of the minimum $T_{s k}$, respectively (bootstrapping test, both $P<0.05$ ).

We used flight-induced acceleration changes to identify potential flight bouts and identified 55 flight bouts with a wingbeat frequency greater than $5 \mathrm{~Hz}$ (Fig. 3C). The flight bouts had a median wingbeat frequency of $7.2 \mathrm{~Hz}$ (Fig. 3C) and last on average $47.5 \mathrm{~s}$ (Fig. 3D). To quantify the effects of flight on the $T_{s k}$, we extracted the $T_{s k}$ at the beginning of the flight bouts and the maximum $T_{s k}$. The time difference between these two temperature points was referred to as the rise time that consists of both the flight time and the short pauses between the flight bouts. As shown in the zoomed-in view of Fig. 4A, within the rise time window there are four identified flight bouts separated by short pauses during which no wingbeat was recorded. The temperature difference between these two temperature points was referred to as the maximum increase in $T_{s k}$ (Fig. 4A). Additionally, we measured the decay time which was the required time for the maximum $T_{s k}$ to drop to the level at the beginning of the flight onset (Fig. 4A). The median of the maximum increase in $T_{s k}$ of individual bats was $3.4{ }^{\circ} \mathrm{C}$, ranging from 1.9 to $5.3^{\circ} \mathrm{C}$ (Fig. 4B). It took a median of $9 \mathrm{~min}$ for the bats to reach the maximum $T_{s k}$, while it took a median of $25 \mathrm{~min}$ for the $T_{s k}$ to drop to the flight onset level (Fig. 4C). The rise time was significantly shorter than the decay time (Paired one-side $t$-test, t-stat $=-4, P=0.005)$. Accordingly, the rate of $T_{s k}$ change was more rapid for the rising phase than for the decaying phase of the $T_{s k}$ (Fig. 4D; Paired one-side $t$-test, $t$-stat $=2.9, P=0.018$ ). Note, the decay time could not be estimated for two individuals because the $T_{s k}$ of the bats remained high for the entire recording session.

Subsequently, we analyzed the correlation between the maximum increase in $T_{s k}$ and three temporal parameters: the rise time, the decay time, and the flight time. We
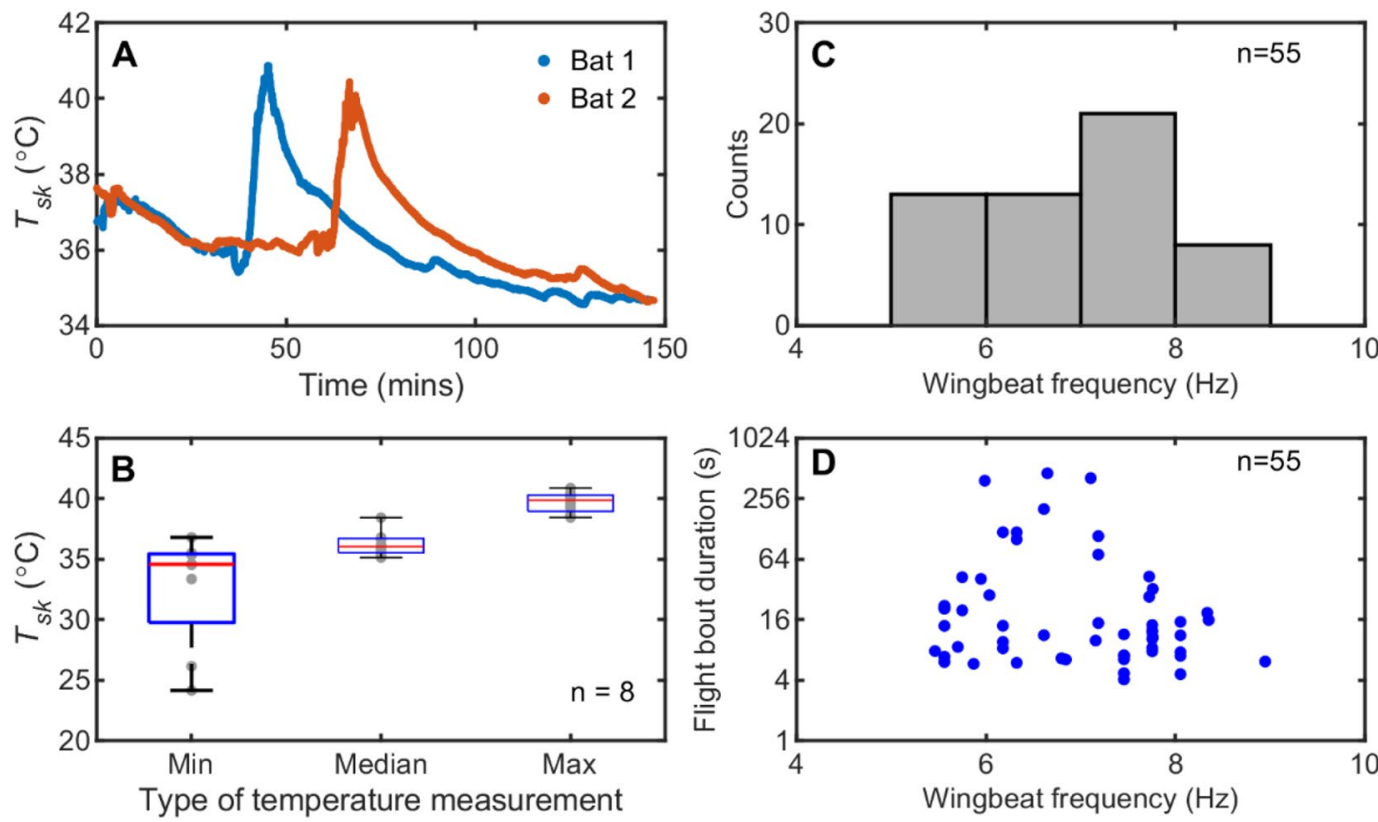

Fig. 3 Characteristics of the body temperature and the flight behavior for flying bats in the laboratory. A Continuous recording of the $T_{s k}$ of two bats for the entire experimental session lasting for approximately two and a half hours. Time zero is the beginning time of the recording. $\mathbf{B}$ The minimum, median, and maximum $T_{s k}$ of all eight bats recorded in the laboratory. Grey circles indicate the data of individual bats. C Counts of the wingbeat frequency of the bats based on accelerometer measurements with a bin size of $1 \mathrm{~Hz}$. $\mathbf{D}$ Duration of the flight bouts in relation to the wingbeat frequencies. The sample size is indicated by the associated number 

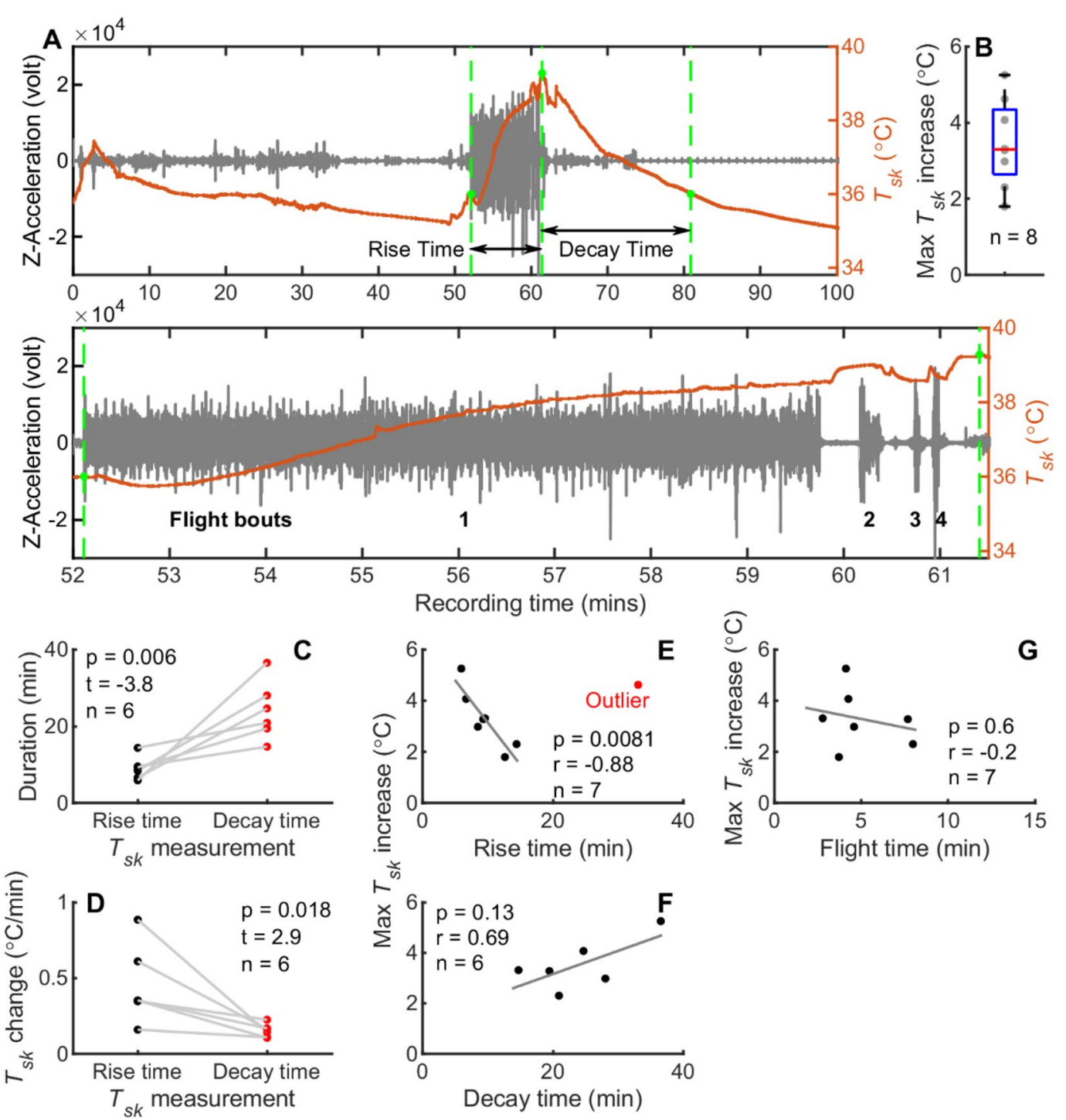

Fig. 4 Body temperature dynamics in flying bats in the laboratory. A Synchronized recordings of the skin temperature $\left(T_{s k}\right)$ and flight behavior (as reflected by the Z-acceleration data). The rise time is measured as the time difference between the $T_{s k}$ of the flight onset (left green circle) and the maximum $T_{s k}$ (center green circle). The decay time is measured as the time difference between the maximum $T_{s k}$ (center green circle) and the post-flight $T_{s k}$ that equals to the $T_{s k}$ at the flight onset (right green circle). The rise time and the decay time (i.e., a measurement of duration) consists of both the flight time and the short pauses between the flight bouts when no wingbeat was recorded. As shown in the zoomed-in view, there are four individual flight bouts separated by short pauses within the rise time window. Nevertheless, the decay time is largely dominated by the time when the bat is resting. (B) The maximum increases in $T_{s k}$ after the flight events. The grey circles were the data of individual bats. C, D A comparison of the total time length (duration) and the rate of the $T_{s k}$ changes between the $T_{s k}$ rising and decaying periods. E, F, $\mathbf{G}$ The maximum increases in $T_{s k}$ seem to be negatively related to the rising time, positively related to the decay time, but unrelated to the flight time. Note, flight time here is the sum of separated flight bouts within the rise time window. For the statistical tests of $\mathbf{E}$ and $\mathbf{G}$, the outlier data point was excluded. Note, we had a very small sample size (individuals) that probably limited our ability to detect a statistical significance for data in $\mathbf{E}$ and $\mathbf{F}$. The sample size for each group is indicated by the associated number

found that the maximum increase in $T_{s k}$ was negatively related to the rise time, after excluding one outlier data point (Fig. 4E; Pearson correlation, $R=-0.87, P=0.011$ ). In other words, the faster the $T_{s k}$ rises, the greater the maximum increase in $T_{s k}$. There is a strong trend that the greater the maximum increase in $T_{s k}$, the longer the decay time (Fig. 4F). However, there was no indication that the maximum increase in $T_{s k}$ correlated with the total flight time (Fig. 4G; Pearson correlation, $R=-0.09$, $P=0.85$ ). 
Body temperature and flight behavior of free-ranging $\mathrm{H}$. armiger in the field

To study body temperature dynamics in the wild, 10 $H$. armiger individuals were tagged and released (see "Methods"). In total, we recovered dataloggers from five individuals, four of which had data. Nevertheless, we only identified clear flight bouts from two of these four bats. We plotted the synchronized $T_{s k}$ and acceleration data for a bat with clear flight bouts (Fig. 5A, $\mathrm{B})$. Figure $5 \mathrm{~B}$ shows a zoomed-in view of the flight bouts from the field and the laboratory recording. We found that the wingbeat frequencies were similar in these recordings (Fig. 5C; Wilcoxon rank-sum test, $\mathrm{z}$-value $=0.46, P=0.64$ ). By contrast, the flight bouts in the field were characterized by acceleration with greater amplitude than those in the laboratory (Fig. 5C; Wilcoxon rank-sum test, $\mathrm{z}$-value $=-7.6$, $P<0.001$ ), although the causes or the implications of this difference are unknown.

\section{Discussion}

Methods for measuring the body temperature of bats

To date, three main techniques have been used to measure the body temperature of bats: thermocouples, light-weight temperature sensors, and thermal infrared imaging cameras. In recent years, light-weight temperature sensors have become a popular and dominant method for studying bats' body temperature (Fig. 2A). Specifically, for research conducted after 2000, temperature sensors were used in $73 \%$ of the studies. One advantage of the temperature sensor, compared to the traditional thermocouples, is its capability for recording the body temperature of freely behaving animals continuously. Although the thermal infrared imaging method also allows measuring the body temperature of freely behaving animals, these cameras are far more expensive. Previous studies have shown that in small animals the $T_{s k}$ can accurately represent the core body temperature, particularly when the $T_{s k}$ was measured subcutaneously as in our case [28]. Indeed, our limited calibration data showed that there were on average only $0.4{ }^{\circ} \mathrm{C}$ difference
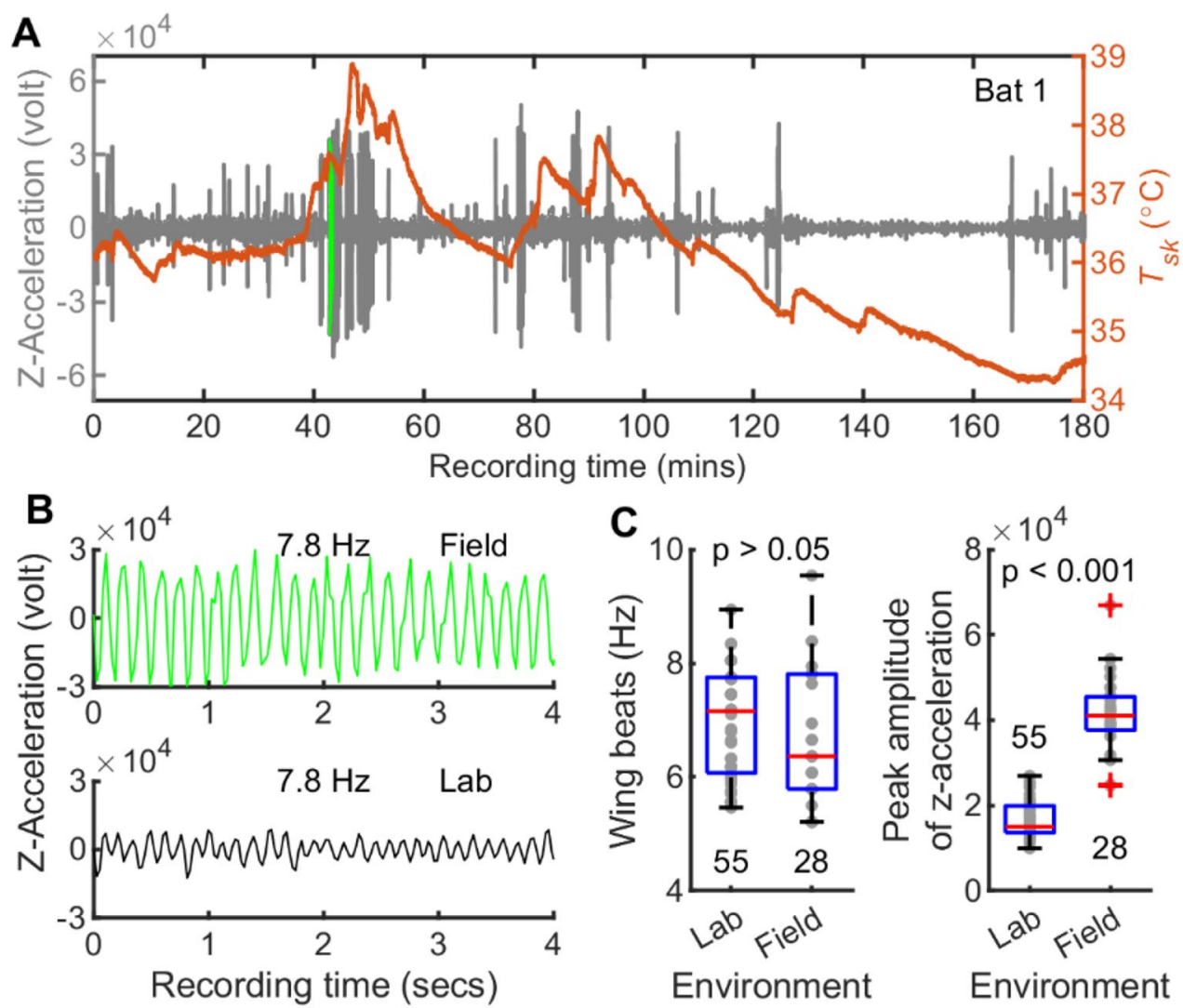

Fig. 5 Measuring body temperature and flight behavior of free-ranging bats in the field. A Example recordings of $T_{s k}$ and flight-induced accelerations in a bat with identifiable flight bouts from the field. B Zoomed-in views of flight bouts from the field (highlighted in green of $\mathbf{A}$ ) and from the laboratory. C Comparisons of the wingbeat frequency and the peak amplitude of z-acceleration between the field and laboratory recordings. The grey circles indicate the data of individual bats. The sample size for each group is indicated by the associated number 
between the core body temperature and $T_{s k}$ measured subcutaneously (Additional file 1: Fig. S1B). Note, the $T_{s k}$ measurements are closely related to, but can be different from, the core body temperature as measured rectally [ 5 , $28,29]$. One critical factor that affects the accuracy of the $T_{s k}$ for representing the core $T_{b}$ is the air temperature. Thus, a second temperature sensor for measuring the air temperature should be added for studying bats in an environment where the air temperature fluctuates across the recording period.

\section{Effects of flight on body temperature of bats}

Bats are the only mammals capable of powered flight. The unique flight capability raises the question of how flapping flight affects bats' body temperature $[9,30]$. Because flight in bats requires on average twice the energy of running mammals of similar body size, both the respiratory rate and the heart rate increase dramatically during the flight [31]. The high metabolic rate of flapping flight in bats poses a danger of overheating [3]. Here, we provide evidence that flight induces an increase in the body temperature of bats, with an amount of $3.4^{\circ} \mathrm{C}$ (between 1.9 and $5.3^{\circ} \mathrm{C}$ for different individuals) in the laboratory. Assessing the effects of flight on body temperature in the field is more challenging, due to the limited acceleration data available. Nevertheless, as shown in Fig. 5A, it seems that the maximum increase in the body temperature in the free-ranging bats in the field $\left(\sim 3^{\circ} \mathrm{C}\right)$ is similar to that in the laboratory. A median of $3.4^{\circ} \mathrm{C}$ increase in $T_{s k}$ associated with flight is similar to reports for some bat species $\left(\sim 4{ }^{\circ} \mathrm{C}\right)$ [30], as well as for some birds [32], but slightly smaller than that reported for Phyllostomus hastatus of about $5{ }^{\circ} \mathrm{C}$ [4]. If we use the lowest and the median $T_{s k}$ during the recording session as a reference for calculating the maximum increase in $T_{s k}$ due to the flight, the median values would be 5.3 and $3.8^{\circ} \mathrm{C}$, respectively. Thus, they become closer to those reported for other bat species.

The maximum $T_{s k}$ recorded for the bats in the laboratory was narrowly centered at $40{ }^{\circ} \mathrm{C}$ (between 38.5 and $40.9{ }^{\circ} \mathrm{C}$ ). Previous research showed that the $T_{s k}$ is usually lower than the $T_{b}$, but the maximum difference is no greater than $3.3^{\circ} \mathrm{C}$ [28]. It was also shown that at an air temperature greater than $20{ }^{\circ} \mathrm{C}$ that is true for our measurements, the actual difference between $T_{s k}$ and $T_{b}$ would be smaller than $2{ }^{\circ} \mathrm{C}$ [29]. Thus, it seems that the bats actively maintained the maximum body temperature below the lethal level of $44-45{ }^{\circ} \mathrm{C}$ [31]. Again, the observed maximum body temperatures during the flight are consistent with flying birds [32], as well as a range of non-flying mammals [28].

Several mechanisms have been proposed to facilitate heat dissipation of flying bats to maintain the body temperature below the lethal level, such as the special membrane structure of bat wings and the increased airflow during wing flapping [3]. One interesting finding from this study is that the longer the rise time, the smaller the maximum increase in $T_{s k}$. This finding suggests that the bats can potentially slow down the body temperature increase with intermittent flights, as compared with a continuous flight. Indeed, it has been observed that some bat species, such as Pteropus poliocephalus, cannot maintain continuous flight for even a few minutes at an air temperature $>24^{\circ} \mathrm{C}$ [33], although it is unknown whether $H$. armiger similarly becomes hyperthermic with prolonged flight. $H$. armiger is a bat species that scan and detect fluttering insects from perches. This perch searching behavior is suggested to be a strategy in conserving energy and serves to compensate for the energetically expensive hunting with the short sallying flights from a perch [34]. Here, we suggest that, in addition to optimizing the energy efficiency, perch-hunting behavior that results in intermittent flights may function as a thermoregulatory strategy to avoid fatal hyperthermia.

\section{Conclusions}

In this study, we made synchronized recordings of the body temperature and flight behavior with onboard dataloggers in a perch-hunting bat species. Our data provide evidence that flight affects the body temperature of flying bats and bats regulate the maximum body temperature within a narrow range below the lethal values of hyperthermia. The skin temperature changes induced by flight nicely corroborated earlier studies, thus providing putative evidence that skin temperature measurements used with onboard miniature temperature sensors can be a useful tool for studying flying bat physiology. This study also revealed one interesting and potential behavioral strategy that can be used by the bats to control the body temperature, namely the intermittent flight associated with the perch-hunting behavior of some species of bats. Furthermore, we want to emphasize that bat species that use perch-hunting strategies for foraging, mainly those from the Rhinolophidae and Hipposideridae families, were least studied for thermophysiology, as our literature survey reveals. Lastly, we presented pilot data to show that these dataloggers can be applied to study the effects of flight on body temperature in freely ranging bats in the real world.

\section{Methods}

\section{Animals and dataloggers}

All experiments were performed with permission from the National Research Council of Thailand (NRCT), with the consent of the Department of National Park, Wildlife and Plant Conservation (DNP)-permit number 
0002/2865. In total, 18 Hipposideros armiger bats were caught in the Satun cave in Thailand $\left(6^{\circ} 59^{\prime} 34.32^{\prime \prime} \mathrm{N}, 100^{\circ}\right.$ $8^{\prime} 26.48$ "E using hand nets, and each bat was tagged with a miniature data logger (Vesper, ASD Inc. Israel, see https://asd-tech.com/products/ for technical specs). The vespers included a synchronized temperature sensor (LMT86, Texas Instruments, Texas, USA) and a 3D accelerometer (Inversense, inc). The device was mounted on the back of the bats right in between the shoulders using surgical cement (Permatype inc.). The temperature sensor, protruding from the device was inserted subcutaneously by making a slit in the skin $(0.5 \mathrm{~cm}$ long, which was glued using the cement). The temperature sensor sampled the data at a rate of approximately $1200 \mathrm{~Hz}$ and the acceleration sensor sampled the data at a rate of approximately $40 \mathrm{~Hz} .10$ bats were studied in the field and these bats were also mounted with a telemetry unit (Holohil Systems Ltd. Carp, Ontario, Canada) to ease the finding of the GPS device after it falls off the bats. $H$. armiger is one of the largest echolocating bat species and we only tagged individuals that weighed $>50 \mathrm{~g}$. The device's average weight was $5 \mathrm{~g}$, thus accounting for $\leq 10 \%$ additional loading on the animal's weight, which was already shown to be feasible for a bat to carry while commuting and foraging $[35,36]$. The remaining 8 bats were used for the laboratory study. Here, the animals were released in a $3 \times 2 \times 2 \mathrm{~m}^{3}$ room and encouraged to fly for a few minutes typically. In between the experiments in the laboratory, the bats were kept in handbags at room temperature and they were released at the capture site on the same day or the next day after removing the tags. They were fed mealworms and offered water. For the field experiment, tags were retrieved within 10 days either by collecting them from the cave's ground or by recapturing the bats. To our best knowledge, tags did not remain on the bats for more than 10 days.

We validated that the $\mathrm{z}$-acceleration measurements are correlated with wingbeat in four flying bats (Additional file 1: Fig. S2). As shown in Additional file 1: Fig. $\mathrm{S} 2 \mathrm{~A}$, a multi-video camera system revealed a wingbeat frequency of $8.2 \pm 0.6 \mathrm{~Hz}$ in a bat flying in a large flight room $(5.5 \times 4.5 \times 2.5 \mathrm{~m})$. Also, Additional file 1: Fig. S2B shows that the Z-acceleration data are synchronized with the wingtip tracking in another bat species where we had both video and acceleration data [37]. The details for the multi-camera tracking system and motion analysis can be found in a previous study.

\section{Data analysis}

All data were analyzed in MATLAB with customer scripts (version 2018b, Mathworks, Natick, MA, USA). The raw data from which specific measurements were made are shown in Fig. $1 \mathrm{~A}-\mathrm{C}$. Since recordings of the temperature and acceleration data are synchronized with the same sampling clock, the sampling time was used as a reference to examining the relationship between body temperature and flight behavior. For acceleration data, we only analyzed the $\mathrm{z}$-axis recording which reflects the wingbeat cycles [38]. To calculate the wingbeat frequency, short-time Fourier transformation of the $\mathrm{z}$-axis acceleration data was used and the outputs were averaged across time, from which the wingbeat frequency was estimated as the frequency peak (Fig. 1D; 128-point window size with $90 \%$ overlapping between adjacent frames). These settings give a frequency resolution of about $0.3 \mathrm{~Hz}$. Wingbeat frequency was estimated for each identified flight bout and manually inspected to confirm the quality. Assuming a flight speed of the bat in the laboratory is $3 \mathrm{~m} / \mathrm{s}$, and a body mass of $60 \mathrm{~g}$, the wingbeat frequency predicted based on scaling-laws for our bats is $7.9 \mathrm{~Hz}$ [39], which is consistent with empirical measurements from a recent study [40].

We identified the flight bouts from the z-axis acceleration data with a fixed amplitude threshold after applying a $2 \mathrm{~Hz}$ high-pass Butterworth filter ( $4^{\text {th }}$ order) to prevent low-frequency noise. The amplitude threshold was set to 1000 and 5000 for the laboratory and field acceleration data, respectively. We used a higher amplitude threshold for the field recording because the recordings in the field were much greater in amplitude than those in the laboratory. A flight bout was defined as a section of continuous oscillation with the absolute amplitude of the samples exceeding the specified amplitude threshold and its duration no shorter than $4 \mathrm{~s}$. This artificially set duration threshold guaranteed at least 160 data samples (40 Hz sampling frequency for the acceleration data) to perform a 128-point (FFT size) spectral analysis. Within the flight bout, the duration of continuous samples with their amplitude lower than the specified amplitude threshold is no longer than one second. The processes for identifying the flight bouts are essentially the same for identifying acoustic events as described in previous studies $[41,42]$. With these criteria, 18 flight bouts had a wingbeat frequency below $5 \mathrm{~Hz}$, which is unusually slow for our bats (see above). Furthermore, despite a dominant lower frequency peak, these low wingbeat flight bouts often contain a secondary frequency peak above $5 \mathrm{kHz}$ of yet smaller amplitudes. Thus, these slow-wingbeat flights were excluded from further analysis.

\section{Literature survey}

To better understand the progression of the techniques applied for measuring bat body temperature over the years, we performed a systematic literature survey on studies of the body temperature in bats. Firstly, we used combinations of keywords to identify relevant studies 
from the database Web of Science (http://www.webof knowledge.com/). Specifically, in the Advanced Search window, the search terms TS =("bats" AND "body temperature") OR TS $=$ ("bats" AND "core temperature") OR $\mathrm{TS}=$ ("bats" AND "skin temperature") OR TS $=($ "bats" AND "active temperature") were used, which returned 509 studies. Subsequently, we went through the title, abstract, and keywords of each study, and excluded 347 studies. We excluded these studies either because no body temperature data were collected or that the study subjects were not bats. Additionally, we excluded one study that the body temperature was measured after scarifying the animal, and six studies in which the body temperature was measured for anesthetized animals. Lastly, we supplemented the identified literature list with relevant studies from our personal library. In total, we identified 179 studies on the body temperature of bats (Additional file 1: Table S1).

\section{Supplementary Information}

The online version contains supplementary material available at https://doi. org/10.1186/s40317-021-00268-6.

Additional file 1: Fig. S1. Calibrated measurements of the skin temperature, core body temperature, and air temperature of a flying $\mathrm{H}$. armiger in the laboratory. Fig. S2. Calibrations of the accelerometers with flying bats. Table S1. The List of studies on the body temperature of bats.

\section{Acknowledgements}

We thank A. Boonman for technical assistance during the project.

\section{Authors' contributions}

SG collected the data, with supports from SB; HY performed the literature survey; OE calibrated the loggers; $J \mathrm{~L}$ and $\mathrm{HY}$ analyzed the data, with support from $Y Y ; j L$ and $Y Y$ wrote the manuscript. $Y Y$ supervised the project. All authors read and approved the final manuscript.

\section{Funding}

$J L$ was funded by the National Natural Science Foundation of China (31970426) and a Career Development Award from the Human Frontier Science Program (CDA00009/2019-C). SG was supported by the Sagol School of Neuroscience, Tel Aviv University.

\section{Availability of data and materials}

The data sets used and analyzed during the current study are available from the corresponding author on request.

\section{Declarations}

Ethics approval and consent to participate

Not applicable.

\section{Consent for publication}

Not applicable.

\section{Competing interests}

The authors declare that they have no competing interests.

\section{Author details}

${ }^{1}$ Hubei Key Laboratory of Genetic Regulation \& Integrative Biology, School of Life Sciences, Central China Normal University, Wuhan, China. ${ }^{2}$ School of Zoology, Faculty of Life Sciences, Tel Aviv University, Tel Aviv, Israel. ${ }^{3}$ Sagol School of Neuroscience, Tel Aviv University, Tel Aviv, Israel. ${ }^{4}$ Department of Biology, Prince of Songkla University, Hat Yai, Songkhla, Thailand.

Received: 24 December 2020 Accepted: 22 October 2021

Published online: 03 November 2021

\section{References}

1. Fenton MB, Simmons N. Bats: a world of science and mystery. Brooklyn, New York: University of Chicago Press; 2014.

2. Burbank RC, Young JZ. Temperature changes and winter sleep of bats. J Physiol. 1934;82:459-67.

3. Stones RC, Wiebers JE. A Review of Temperature Regulation in Bats (Chiroptera). Am Midl Nat. 1965;74:155-67.

4. Thomas SP, Suthers RA. The physiology and energetics of bat flight. J Exp Biol. 1972;57:317-35.

5. Willis CKR, Brigham RM. Defining torpor in free-ranging bats: experimental evaluation of external temperature-sensitive radiotransmitters and the concept of active temperature. J Comp Physiol B. 2003;173:379-89.

6. Geiser F. Metabolic rate and body temperature reduction during hibernation and daily torpor. Annu Rev Physiol. 2004;66:239-74.

7. Stawski C, Willis CKR, Geiser F. The importance of temporal heterothermy in bats. J Zool. 2014;292:86-100.

8. Doty AC, Currie SE, Stawski C, Geiser F. Can bats sense smoke during deep torpor? Physiol Behav. 2018;185:31-8.

9. Reeder WG, Cowles RB. Aspects of thermoregulation in bats. J Mammal. 1951;32:389-403.

10. O'Farrell MJ, Bradley WG. Comparative thermal relationships of flight for some bats in the Southwestern United States. Comp Biochem Physiol A Physiol. 1977;58:223-7.

11. Voigt CC, Lewanzik D. Trapped in the darkness of the night: thermal and energetic constraints of daylight flight in bats. Proc R Soc B. 2011;278:2311-7.

12. O'Shea TJ, Cryan PM, Cunningham AA, Fooks AR, Hayman DTS, Luis AD, et al. Bat flight and zoonotic viruses. Emerg Infect Dis. 2014;20:741-5.

13. Luis AD, Hayman DTS, O'Shea TJ, Cryan PM, Gilbert AT, Pulliam JRC, et al. A comparison of bats and rodents as reservoirs of zoonotic viruses: are bats special? Proc R Soc B. 2013;280:20122753.

14. Moreno KR, Weinberg M, Harten L, Ramos VBS, et al. Sick bats stay home alone: fruit bats practice social distancing when faced with an immunological challenge. Ann N Y Acad Sci. doi: https://doi.org/10.1111/nyas. 14600.

15. Hock RJ. The metabolic rates and body temperatures of bats. Biol Bull. 1951:101:289-99.

16. Morrison P. Body temperatures in some Australian mammals I chiroptera. Biol Bull. 1959;1 16:484-97.

17. Luo J, Clarin B-M, Borissov IM, Siemers BM. Are torpid bats immune to anthropogenic noise? J Exp Biol. 2014;217:1072-8.

18. Hamilton IM, Barclay RMR. Patterns of daily torpor and day-roost selection by male and female big brown bats (Eptesicus fuscus). Can J Zool. 1994;72:744-9.

19. Hickey MBC, Fenton MB. Behavioural and thermoregulatory responses of female hoary bats, Lasiurus cinereus (Chiroptera: Vespertilionidae), to variations in prey availability. Écoscience. 1996;3:414-22.

20. Chruszcz BJ, Barclay RMR. Thermoregulatory ecology of a solitary bat, Myotis evotis, roosting in rock crevices. Funct Ecol. 2002;16:18-26.

21. Turbill C, Körtner G, Geiser F. Timing of the daily temperature cycle affects the critical arousal temperature and energy expenditure of lesser longeared bats. J Exp Biol. 2008;211:3871-8.

22. Levin E, Plotnik B, Amichai E, Braulke LJ, Landau S, Yom-Tov Y, et al. Subtropical mouse-tailed bats use geothermally heated caves for winter hibernation. Proc R Soc B. 2015;282:20142781.

23. Lancaster WC, Thomson SC, Speakman JR. Wing temperature in flying bats measured by infrared thermography. J Therm Biol. 1997;22:109-16.

24. Reichard JD, Fellows SR. Thermoregulation during flight: Body temperature and sensible heat transfer in free-ranging Brazilian free-tailed bats (Tadarida brasiliensis). Physiol Biochem Zool. 2010;83:885-97. 
25. Reichard JD, Prajapati SI, Austad SN, Keller C, Kunz TH. Thermal windows on Brazilian free-tailed bats facilitate thermoregulation during prolonged flight. Integr Comp Biol. 2010;50:358-70.

26. Rummel AD, Swartz SM, Marsh RL. Warm bodies, cool wings: regional heterothermy in flying bats. Biol Let. 2019;15:20190530.

27. Leitner P. Body temperature, oxygen consumption, heart rate and shivering in the California mastiff bat Eumops perotis. Comp Biochem Physiol. 1966;19:431-43.

28. Barclay RMR, Kalcounis MC, Crampton LH, Stefan C, Vonhof MJ, Wilkinson $L$, et al. Can external radiotransmitters be used to assess body temperature and torpor in bats? J Mammal. 1996;77:1102-6.

29. Audet D, Thomas DW. Evaluation of the accuracy of body temperature measurement using external radio transmitters. Can J Zool. 1996;74:1778-81.

30. Thomas SP, Follette DB, Farabaugh AT. Influence of air temperature on ventilation rates and thermoregulation of a flying bat. Am J Physiol. 1991;260:R960-8.

31. Neuweiler G. The Biology of Bats. New York: Oxford University Press; 2000

32. Adams NJ, Pinshow B, Gannes LZ, Biebach H. Body temperatures in freeflying pigeons. J Comp Physiol B. 1999;169:195-9.

33. Carpenter RE. Flight physiology of flying foxes, pteropus poliocephalus. J Exp Biol. 1985;114:619-47.

34. Voigt CC, Schuller B-M, Greif S, Siemers BM. Perch-hunting in insectivorous Rhinolophus bats is related to the high energy costs of manoeuvring in flight. J Comp Physiol B. 2010;180:1079-88.
35. Harten L, Katz A, Goldshtein A, Handel M, Yovel Y. The ontogeny of a mammalian cognitive map in the real world. Science. 2020;369:194-7.

36. Egert-Berg K, Hurme ER, Greif S, Goldstein A, Harten L, Herrera MLG, et al. Resource ephemerality drives social foraging in bats. Curr Biol. 2018;28:1-7.

37. Eitan $\mathrm{O}, \mathrm{Kosa} \mathrm{G}$, Yovel Y. Sensory gaze stabilization in echolocating bats. Proc R Soc B. 2019;286:20191496.

38. Stidsholt L, Johnson M, Beedholm K, Jakobsen L, Kugler K, Brinkløv S, et al. A 2.6-g sound and movement tag for studying the acoustic scene and kinematics of echolocating bats. Methods Ecol Evol. 2019;10:48-58.

39. Bullen RD, McKenzie NL. Scaling bat wingbeat frequency and amplitude. J Exp Biol. 2002;205:2615-26.

40. Windes P, Tafti DK, Müller R. Analysis of a 180-degree U-turn maneuver executed by a hipposiderid bat. PLoS ONE. 2020;15:e0241489.

41. Luo J, Goerlitz HR, Brumm H, Wiegrebe L. Linking the sender to the receiver: Vocal adjustments by bats to maintain signal detection in noise. Sci Rep. 2015;5:18556

42. Lu M, Zhang G, Luo J. Echolocating bats exhibit differential amplitude compensation for noise interference at a sub-call level. J Exp Biol. 2020;223:225284

\section{Publisher's Note}

Springer Nature remains neutral with regard to jurisdictional claims in published maps and institutional affiliations.
Ready to submit your research? Choose BMC and benefit from:

- fast, convenient online submission

- thorough peer review by experienced researchers in your field

- rapid publication on acceptance

- support for research data, including large and complex data types

- gold Open Access which fosters wider collaboration and increased citations

- maximum visibility for your research: over $100 \mathrm{M}$ website views per year

At BMC, research is always in progress.

Learn more biomedcentral.com/submissions 